\title{
Mapping the Imagination: Distinct Acts, Objects, and Modalities
}

\section{Rudolf Bernet}

\section{Husserl Studies}

ISSN 0167-9848

Volume 36

Number 3

Husserl Stud (2020) 36:213-226

DOI 10.1007/s10743-020-09272-9 
Your article is protected by copyright and all rights are held exclusively by Springer Nature B.V.. This e-offprint is for personal use only and shall not be self-archived in electronic repositories. If you wish to self-archive your article, please use the accepted manuscript version for posting on your own website. You may further deposit the accepted manuscript version in any repository, provided it is only made publicly available $\mathbf{1 2}$ months after official publication or later and provided acknowledgement is given to the original source of publication and a link is inserted to the published article on Springer's website. The link must be accompanied by the following text: "The final publication is available at link.springer.com". 


\title{
Mapping the Imagination: Distinct Acts, Objects, and Modalities
}

\section{Rudolf Bernet $^{1}$ (D)}

Published online: 7 September 2020

(c) Springer Nature B.V. 2020

\begin{abstract}
This article begins by presenting the two most important transformations that establish a genuine Husserlian approach to the imagination: the first lies in the grasping of imagination, despite its essential differences with perception and hallucination, as an intuitive, or sensuous consciousness (thereby contrasting it with signification); the second lies in the insight that imagination, or better - phantasy -, requires no images, mental or otherwise (thereby contrasting it with image consciousness). Further, the distinction between pure and perceptual phantasies and their respective fictional objects is drawn out. A comparison between pure phantasy and memory, then leads to a closer look at the role of inner consciousness in pure phantasy and to a clarification of the 'splitting of the subject'. The exploration of this split allows us to trace the role of the real-ego and the phantasy-ego in pure phantasy, which opens the exploration of phantasy as a consciousness of possibilities. This helps us gain clarity about the nature of both real and ideal possibilities and the respective modes of phantasy. Objects of phantasy also most easily lend themselves to an eidetic variation and to an insight into essences. Phenomenological essences concern the ideal possibility of real and ideal objects and of their experience. It is through their contribution to insight into the real and ideal conditions of possibility of different forms of intentional acts that acts of phantasy best show their potential for Husserl's project of philosophy as a rigorous science. Imagination or fiction becomes, in his own words, the 'vital element of phenomenology.'
\end{abstract}

The analysis of imagining occupies a central place in Husserl's exploration of the different forms and modalities of intentional consciousness. Retracing Husserl's footsteps, we will explore the essential difference between acts of a pure phantasy or quasi-perception and acts which represent an object by means of an image or a sign - without losing view of everything which separates the intuitive givenness of an imaginary object from the perceptive givenness of a real object. We will also pay

Rudolf Bernet

Rudolf.Bernet@kuleuven.be

1 Katholieke Universiteit Leuven, Leuven, Belgium 
attention to how the imaginative re-presentation (Vergegenwärtigung) of an unreal intentional object differs from remembering the real object of a past experience. It will soon appear, however, that the opposition between objects that really exist, and objects that have no actual existence, is insufficient to fully account for the nature of acts of imagination and their intentional objects.

Imagined unreal or fictional objects can, indeed, also be objects of a possible real experience. Imagined objects can possibly become real objects and then lend themselves to an actual perception. For this, the content of imagination must comply with both objective and subjective conditions of possibility. Only when these conditions are fulfilled, can the possibility of imagined objects becoming real objects, be realized and merit the name 'real possibility.' On the other hand, it is because they are not taken to really exist, that objects of imagination lend themselves to a (phenomenological) insight into the essential constituents of a certain type of object. For Husserl, an essence concerns what real and unreal objects of a certain kind necessarily have in common. As such, an essence has a kind of ideal existence that operates as an (ontological and logical) condition of possibility for all real and unreal individual objects of its kind. Essences or essential laws thus concern the ideal possibility of objects and of their experience. Despite being unreal in the sense of an empirical, mundane reality, essences and other kinds of ideal objects have a reality of their own, which Husserl calls 'irreal.' Thus, in addition to the central role it plays in Husserl's theory of intentional consciousness, the imagination also participates in his phenomenological investigation of the logical/ontological and modal categories of reality/unreality/irreality, (real and ideal) possibility/impossibility, and necessity/ contingency.

No wonder then, that Husserl's analysis of imagination has a central impact on his entire philosophical project. This is already true for the phenomenological method, whose most essential moments - such as the epoché, the transcendental reduction and the eidetic reduction - are most closely related to the refraining from positing the real existence of empirical objects. The rupture with the course of natural life, the attention to the essence of a thing independently of its empirical context, the discovery of how the being and meaning of an object depend on how it is given and subjectively intended: these are fundamental insights that phenomenology largely owes to its description of imagination. ${ }^{1}$ Imagination or fiction thus becomes, in Husserl's own words, the "vital element of phenomenology" (Hua III, 1, § 70), ${ }^{2}$ and in particular of a phenomenological analysis of intentional consciousness. In what follows, we will also pay attention to how imagination leads Husserl to refine his analysis of the 'inner' consciousness of different kinds of intentional acts, and how,

\footnotetext{
1 This is not to say, of course, that the neutralization of the belief in the existence of the real world, which is at stake in the case of the epoché, involves an explicit act of imagination and its specific kind of neutrality towards the real existence of its (fictive) objects. Equally, despite the fact that imagination naturally draws our attention to the intentional correlation between act and object, it does not automatically lead to a transcendental understanding of this correlation and its 'constitutive' performance.

${ }^{2}$ For full references to the Husserliana volumes (Hua hereafter), see the shared bibliography, at the end of the guest editors' introduction, for the special issue this paper is part of.
} 
in imagination, intentional consciousness divides itself into separate modes of life through a scission of the ego, or subject of experience.

\section{Pure Phantasy: Imagination Without Signs or Images}

With each of the two major transformations in the Husserlian conception of imagining consciousness, there is a deepening and an enriching of his understanding of the imaginary mode of the presence of an object. This also entails a transformation of Husserl's phenomenological understanding of both the perceptual presence of an object and of its symbolically signified presence.

In distancing himself from understanding imagination as an 'inauthentic' (uneigentlich) representation in the Brentanian sense of the term, the first transformation establishes imagination, once and for all, as an intuitive and sensuous form of intentional consciousness. The imaginary in the sense of 'acts of phantasy' is thus cut loose from a mathematical conception of the imaginary. The radical separation between intuitive imagination or phantasy and signifying acts also entails, quite notably, that the givenness of the improperly or emptily appearing moments of a perceived external object (for example its unperceived backside) can no longer be confused (as was still the case in the Logical Investigations) with a subjective representation by means of a sign or a 'signitive partial intention'. Such an inauthentic mode of appearance (uneigentliche Erscheinung) of the object within an act of perception is entirely different from merely imagining or inferring it.

The second transformation of the Husserlian conception of imagination has to do with the discovery of a new form of difference which, this time, exclusively concerns the re-presenting (vergegenwärtigend) consciousness itself - even though it will also have certain implications for the understanding of acts which present (gegenwärtigen) their object. When elaborating his new analysis of pure phantasy (reine Phantasie), Husserl introduces a radical distinction between acts of imagination that re-present an absent object by means of an (external or internal) image, and acts of pure phantasy. We will see that this new and updated theory of pure phantasy as a neutralized or non-positional re-presentation of an absent (fictive) object goes together with a more precise account of how the subject is internally conscious of the effectuation of an act of phantasy, and also with a deepened understanding of remembering (Wiedererinnerung) as another form of an intuitive re-presentation of an absent (real) object. The new analysis of pure phantasy will also have a decisive influence on the analysis of an aesthetic perception (or perceptual phantasy) and on the analysis of an appresentation of someone else's mental life. The latter involves a re-presentation more analogizing than reproductive, which nonetheless must be radically distinguished from an analogy grounded in the presence of an image. This truly revolutionary overhaul of the entire edifice of the phenomenological investigation of different types of objects and different corresponding types of acts or intentional experiences, which follows a refined theory of inner consciousness, would not have been possible without the exploration of the temporal dimension of consciousness, and more particularly, of the inner consciousness of the effectuation of reproductive intentional acts. 


\section{The Neutralization of Reality in Pure and Perceptual Phantasies}

Husserl's pure phantasy is a form of imagination that is cleared of any contamination by reality - even by the reality of an image. It is thus a matter of an intuitive consciousness that freely produces or creates, by dint of its invention, fictive objects and imaginary worlds. As is clearly shown by the example of fantastic tales and mythological stories, such fictive objects and worlds can have their own form of coherence. They are the product of a consciousness, or an attitude sui generis, which is distinguished not only from perceptions in real life, but also from what Husserl calls 'perceptual phantasies.' A perceptual phantasy consists in seeing something unreal (which is to say, having no actual existence), for example seeing King Lear on stage. If such a perceptual phantasy seems to be related to some sort of illusion, the same certainly cannot be said for pure phantasy or imagining phantasy. One must thus clarify the intuitive - but not perceptual - character of pure phantasy as well as the neutralized positing of the existence of its objects, which makes all the difference with perceptual illusions. This presupposes a better understanding not only of the different sorts of conflicts or incompatibilities which characterize, respectively, pure phantasy, perceptual phantasy, and illusory perception, but also a better understanding of the distinction between an illusory semblance (Schein) and an imaginary semblance.

According to the most accepted conception, an illusion is a false perception. It consists, for example, in perceiving a real person when, in truth, there is only a mannequin before me. For me to realize, after the fact, that what I had taken for a perception, was only an illusion, I must have of a new, more correct perception of the object. Once unmasked as an illusion, the former perception ceases to be as much: I can no longer believe either in the object's presence 'in flesh and blood' (leibhaft) or in its actual existence. What prevents me from this is precisely the perceptual givenness of a new, truly existing object. As soon as I come to see that this human form is actually a wax figure, I can no longer perceive it as being a real person. The former illusory perception does not for all that disappear from my consciousness; rather it is preserved as an illusion, or as Husserl says, under the form of a 'crossed-out' (durchgestrichen) perception.

A perceptual phantasy, however, is something different than an illusionary perception for the simple reason that, despite involving an act of real perception, it does not pretend to be the perception of a real object. Adult spectators never believe that what they see on stage is the real King Lear (or the real Julius Cesar); they never perceive the King in the same way as they perceive an attractive person in the first row of the side-balcony. However, they also do not perceive the actor as they perceive that person, that is, independently of the actor's playing King Lear. The spectators rather see Lear in the actor and the actor as Lear. Consequently, the actor and King Lear are too interdependent and too mixed up with each other to allow for any perceptual conflict between them. It is true that, when the acting is good and the fictional drama sufficiently compelling, the spectators completely forget about the actor and only see (or, better, quasi-perceive) Lear and his daughters. However, this will not make them totally blind to the unreal 
character of what they perceive on stage. Even when the spectators lose all interest in the acting of the actor and pay no attention to the surrounding reality, they will not stand up and physically interact with King Lear. A perceptual phantasy is a fiction made visible and not a perceptual reality becoming unreal because of a perceptual conflict.

In both pure phantasy and perceptual phantasy, the neutralizing modification of the positing of the existence of the intentional object is not imposed on the subject by an external conflict affecting the appearing object. The absence of belief or neutralizing modification of the existence of an imaginary object results, on the contrary, from an attitude freely adopted by the subject. In true acts of pure phantasy, the subject deliberately disengages itself from the intercourse with real objects and with the real world. As Husserl's term 'neutralization' suggests, a subject that does not believe in the real existence of the imaginary object, also does not believe in its unreality or non-existence. This is also true for perceptual phantasy. However, in this case the subject does not enjoy the same degree of freedom as in pure phantasy. Unlike the author who wrote the play while freely imagining her story in an act of pure phantasy, the spectator, in her perceptual phantasy, remains constrained by the consistency of the plot that develops before her eyes. Like how an ordinary perceptual object imposes itself on the perceiver and catches her attention, the play on stage awakens a strong interest in the spectator. The fictive perceptual object invites, allures, or even forces her to leave the real world and to enter or participate in the fictional world unfolding in the drama (cf., Hua XXIII, p. 519). It is as if the fictional world displayed before the spectator overtakes her interest in the real world and makes the latter temporarily meaningless.

Speaking of different degrees of freedom in acts of pure and perceptual phantasy, one can also pay attention to their motivation. In perceptual phantasies, the suspension of belief in the real existence of what one sees is often motivated by the vague, changing, or incoherent way a fictional object is presented in the real world. But this is insufficient to explain why, from the beginning, the subject never fully believed in the reality of what it saw. This is even more true in the case of pure phantasy. The freedom of this act can thus be said to be absolute, in the sense that it cannot, in principle, be motivated by any kind of perceptual appearance. Even though the imagination of fictive objects (such as the centaur) often makes use of elements drawn from a perceived reality, one cannot say that a perception (of a real man or of a horse) is what motivates the imaginary re-presentation of a fictive object.

Finally, perceptual and pure phantasies also differ in their mode of neutralization of the existence of the imaginary intentional object. In a perceptual phantasy, the modification of neutrality concerns a perceptual consciousness, which is to say, an act of perception that is actually experienced. By contrast, when I imagine a centaur in an act of pure phantasy, there is no actual perception involved that could be neutralized. The imaginative intuitive givenness of the centaur, far from involving the modification of an actual perception, is rather a givenness that I give to myself. It is one that I create in freely producing the imaginary representation of the centaur. The way in which this centaur is intuitively given to me in an act of pure phantasy 
involves no perception of a real object, the existence of which could or should then be neutralized. ${ }^{3}$ This makes pure phantasy not only a less ambiguous act than perceptual phantasy, but also a more positively productive one. Unmotivated by any kind of actual perception and thus liberated from the concern to distinguish itself from an actual perception, a pure phantasy is not only more free, but also more open and creative than a perceptual phantasy. Pure phantasy is a free and productive act of imagination that can best be characterized as a quasi-perception of a fictive object.

\section{Pure Phantasy and Memory}

How then does consciousness go about freely and creatively producing the fictive objects that are given in a pure phantasy or quasi-perception? The main difficulty stems from the fact that pure phantasy is an act of intuitive re-presentation involving neither the modification of a present actual perception (as is the case for the perceptual phantasy), nor the reproduction of a past actual perception (as is the case with remembering) - even if it shares with perceptual phantasy the fictional character of its intentional object, and with an act of remembering its reproductive nature. Accordingly, one should say that pure phantasy is a reproductive form of consciousness that intuitively re-presents an object whose unreality has the form of a fictive existence. Obviously, more explanation is needed here.

What favors an understanding of pure phantasy as a kind of reproductive consciousness is its similarity to the act of remembering (Wiedererinnerung). Instead of perceptually presenting (gegenwärtigen) a present object, an act of pure phantasy, like remembering, intuitively re-presents (vergegenwärtigt) a physically absent object. For Husserl, this intuitive presence of an absent object is the result, for both pure phantasy and remembering, of a present act of re-presentation intentionally involving or 'implicating' an implicit act of perception. When one remembers a past object, it is presently given as having been experienced in the past. Because it is presently remembered as past, the intentional object of memory cannot be perceived - not even perceived again. Remembering is different from the present repetition of a former perception. However, in an intuitive act of memory, the object re-presented is itself truly given as past. Remembering is thus an act of intuitive re-presentation, where re-presentation means the implication of the former perception of a formerly present object. It is not a re-presentation of a past object by means of a present perception of a present image or sign. Husserl calls the mode in which a former perception is implicated in the present intuitive memory of a past object 'reproduction.'

Likewise, the way a pure phantasy intuitively re-presents its imaginary object, involves no presently perceived present image or sign. Husserl concludes from this, that it must re-present its object by means of an implicated perception that is merely

\footnotetext{
3 This is why Husserl, in the 1920 s, will cease using the term "neutralization" to characterize the absence of a doxical positing concerning the object of a pure phantasy. Given the lack of an original positing of the object, its givenness in the mode of the 'as if' cannot be understood as the result of a neutralized positing (cf., Nr. 20).
} 
imaginary. He also claims that this implication of an imaginary perception must be understood in terms of a reproductive consciousness.

Pure phantasy and intuitive remembering must thus be intentional acts of an intuitive re-presentation of an intentional object that involve the reproduction of an intuitive presentation or perception. There is, however, an important difference between a pure intuitive phantasy and an intuitive memory: memory believes in the existence of the object of the reproduced perception, phantasy does not. Memory also involves the reproduction of a past real perception; phantasy involves the reproduction of a present imaginary perception. For Husserl, this difference manifests itself most fundamentally in the way in which the reproduced - either real or imaginary - act of perception is experienced in the inner consciousness of the subject. In pure phantasy, it is experienced as an unreal perception or as a 'quasi-perception.' This singular mode of the 'quasi' is the expression of the fact that the implicated perception of the imaginary object is not an actual perception of a real object and never has been one in the past. Stated otherwise, the quasi-perception of the fictive object is the modification of an implicit perception that has never actually taken place before being reproduced and modified. In contrast to remembering, it is thus a matter of a reproduction producing the quasi-perception that it reproduces. This operation, at once paradoxical and mysterious, becomes fully comprehensible only with the help of the Husserlian theory of inner consciousness.

\section{Inner Consciousness and the Splitting of the Subject in Pure Phantasy}

According to Husserl's theory of (temporal) inner consciousness, the actual accomplishment of every act - regardless of whether it is an act of presentation or an act of re-presentation - is necessarily accompanied by an implicit impressional awareness, which Husserl (after Brentano) calls 'inner consciousness.' It goes without saying that pure phantasy (like remembering) is such an actually accomplished act and that, as such, it must be impressionally experienced by the inner consciousness of an imagining subject. This cannot be the case for the imaginary perception (reproductively) implicated in the act of a pure phantasy. Unlike the (real) act of a pure phantasy, the implicated (imaginary) perception is not really or straightforwardly effected and never has been so. The mode in which the latter is experienced by inner consciousness can thus not be impressional. One should then say that what inner consciousness experiences in the effectuation of an act of pure phantasy is the actual accomplishment of an intentional act which reproduces the act of an imaginary perception whose re-presented intentional object belongs not to the real world but to a fictive one.

Put differently, the inner consciousness of the effectuation of an act of pure phantasy is the experience of a doubling of intentional consciousness. True, such a doubling of intentional consciousness also happens in memory as well as in all other acts of re-presentation (Vergegenwärtigung) - including image-consciousness. However, unlike in memory or in image-consciousness (where the doubling involves two actual intentional acts), in pure phantasy this doubling of intentional consciousness 
amounts to a veritable form of scission or splitting in subjective life. This is so, because in pure phantasy the reproduced intentional act is merely fictional; it is the quasi-perception of a fictive spectator. Consequently, the (actual) imagining intentional act and the imagined (imaginary or fictive) intentional act belong to different forms of subjective life. This is not the case in remembering, where the (reproductive) present intentional act and the (reproduced) past intentional act are both actual and belong to one and the same actual 'stream of consciousness,' the unity of which is attested by the continuity of an entirely impressional inner consciousness. Equally, this not the case in image-consciousness, where the perception of the image and the quasi-perception of the imaginary object are both actual acts. As such, they are both impressionably experienced, by the inner consciousness of a same actual subject, as belonging into its actual stream of consciousness. In pure phantasy, on the contrary, only the intentional act of a reproductive re-presentation is impressionally experienced by the actual subject, while the (fictive) quasi-perception which it reproduces is not impressionally experienced and has never been. As an intentional act that is not impressionally experienced by the inner consciousness of an actual subject, the quasi-perception implicated in an act of pure phantasy is, as it were, experienced by the actual subject at a distance. The 'quasi' of the quasi-perception involved in an act of pure phantasy would thus not only relate to the actual subject's lack of belief in the actual existence of the imagined object, but also to the fact that the implicated imaginary perception does not belong to its real life. It rather belongs to the fictive life of an another, unreal subject.

\section{The Real-Ego and a Phantasy-Ego Who Lives in an Imaginary Objective World}

This marginalization or separation, in the real life of a subject, of its pure phantasies with their fictive objects, does not exclude that different quasi-perceptions, imagined by a same real subject (or community of real subjects), become interwoven with each other in such a way as to form a coherent and enduring unity of one imaginary life. The intentional correlate of such a unified imaginary life lies in the unity of meaning and duration of one fictive quasi-world or 'phantasy-world' (Phantasiewelt). This last is a world made up by the intentional fictional objects of the imaginary life of an imaginary subject, or 'phantasy-ego' (Phantasie-Ich), who participates in this world in the capacity of a spectator or of an actor (or of both at once). This phantasy-ego - unlike the 'real-ego' (Real-Ich) who actually entertains the phantasies - does not have any reason, itself its, for not believing in the existence of keep as is imaginary world. One could thus say that, within one and the same subject, the unity of parallel lives come to be knitted together, where the life of a phantasy-ego in its phantasy-world forms a sort of simulacrum or imaginary replica of the actual life of the real-ego, such as it takes place in the real world.

Phantasizing belongs to the actual life of the real-ego. Therefore, past acts of a pure phantasy can be remembered in the same way as one remembers one's past acts of actual perception. It is only the content of a phantasy - the phantasized perceptions of a phantasy-ego living in a phantasy-world - that remains irremediably 
separated from the real life of the real-ego in the real world. In contrast to the continuity of the real life of the real-ego in the real world, a phantasy-ego and its fictive world last only as long as a particular phantasy endures, for example, as one that stages a particular myth or fairy tale. We are also not entitled to think that the life of one phantasy-ego in its particular phantasy-world could join up with the life of another phantasy-ego in another imaginary world in such a way as to form a unity of one fictive life in a common imaginary world. There is no more of a community between imaginary worlds than there is between different phantasy-egos. Nothing justifies thinking that the world in which centaurs wreak havoc and the one in which Snow White sleeps her mortal slumber would form one and the same imaginary world. Each phantasy-ego is, on the contrary, a prisoner of her own particular world, and there are as many imaginary worlds as there are phantasy-egos. ${ }^{4}$

There remains, thus, an ineliminable contrast between the imaginary lives enjoyed by diverse phantasy-egos in their fictive worlds, and the actual life led by a real-ego in a real world, which it shares with other real-egos. It is ultimately because of how a particular subject experiences this contrast in inner consciousness that all the objects in which a phantasy-ego places its faith deteriorate into fictive quasi-objects for the real-ego. In an opposite manner to imaginary experiences, all the actual experiences of one and the same real-ego are integrated into the weft and woof of one and the same actual life accomplished in one and the same real world. While the phantasyego and its fictive world lend themselves to a multiplication which is, in principle, unlimited, every actual experience of one and the same real-ego participates in one and the same real life that takes place within one and the same real world. ${ }^{5}$

Yet, since it is nevertheless the same person who simultaneously lives in the real world and in fictive worlds, one must conclude that a human person can simultaneously lead a double life: an actual life and an imaginary one. These two forms of life - despite all their essential differences - are not totally separated, because

\footnotetext{
4 Cf. Bernet (2005).

5 In Part I of Hua XLII Husserl also considers the case of interruptions or 'passages,' such as sleep, in the continuous real life of one and the same real-ego. It seems fair to say that falling asleep, as the 'phenomenon of a passage' (Übergangsphänomen), concerns the real-ego and how she absents herself from her wakeful life in the real world. As a passive activity of the real-ego, falling asleep (or awakening) must furthermore involve an inner consciousness of a radical change in her life. In addition, a sleeper can also become aware of her sleeping when she has an (unpleasant) dream that, however, doesn't awake her. In this case, the unconscious inner awareness the sleeper has of her sleeping, is, as it were, awakened by the contrast between her real-ego that sleeps and her dream-ego(s). She could then say to herself: 'the event is not real, it is only a dream I have, and I am still sleeping'. Despite the similarities between sleepdreaming and acts of imagination, one should not forget that the sleeping real-ego - unlike the awake real-ego that entrains phantasies - does no longer explicitly participate in a real life in the real world. Also, dreams being made of false perceptions (or hallucinations) and not of imagined quasi-perceptions, the dream-ego, unlike the phantasy-ego, is not a quasi-ego but a pretended ego. Finally, and most importantly, the manner in which inner consciousness attends to the contrast or scission between two simultaneous modes of life of a same subject, is different in wakeful imagination and in dreaming sleep. In summary: unlike the events of falling asleep and of awakening, begin and end of an imaginary quasi-life is not an Übergangsphänomen in the real life of a subject; imagining while remaining actively involved in real life, is different from dreaming when one sleeps; the contrast between the life of a wakeful real-ego and of a phantasy-ego is not experienced, by inner consciousness, in the same way as is the double life of a real sleeper who sets the scenery for the illusory lives of dream-egos in dream-worlds.
} 
all imaginary lives and their diverse phantasy-egos are still the product of a real act of intuitive phantasy accomplished by a real-ego. The fictive life of a particular phantasy-ego is thus, for a certain lapse of time, superimposed upon the actual life of the real-ego. Put differently, the fragments or episodes of the multiple imaginary lives of the multiple fictive subjects imagined by a single subject remain anchored in the fabric of that subject's real life. This anchoring of the imaginary in the real, far from being the consequence of a simple logical or metaphysical requirement, is clearly established by the inner consciousness of the real-ego. The imagination of (proper or foreign) fictional lives is also often motivated by (the misfortunes of) one's real life. In addition, the content of a phantasy-world amounts always, to some extent at least, to a modification or variation of the real world. Therefore, a phantasy-world can reveal aspects of the real world that are usually overlooked. However, it is mainly when we imagine something that could possibly be or become real, that phantasy and reality, instead of excluding or merely implicating each other, show their essential complementarity.

\section{The Role of Imagination in the Assumption of Real Possibilities}

In his Revision of the VI. Logical Investigation Husserl makes a distinction between 'real' and 'ideal' possibilities (Hua XX/1, §§ 46-50). A possibility is real, when something, usually an originary intuition, 'speaks for it' (für die etwas spricht) or entices it. On this basis, a real possibility does not only relate to a possible empirical reality. Theoretical or methodological reasons can also speak in favor of the assumption of the possibility of an ideal reality, for example a non-Euclidian space. Consequently, one must make a distinction between real and imaginary possibilities for both empirical and ideal objects. Ideal possibilities can then - for both empirical and ideal objects - be unreal possibilities that one just imagines in an act of phantasy that makes no claim concerning their possible realization, or they can be irreal possibilities or possibilities a priori that are founded on a truly intuitive insight into an essence or an essential law. While latter ideal possibilities can also be real possibilities, this is not the case for the former, merely imaginary possibilities. Further, what speaks for real possibilities can be explicitly and actively grasped or it can be passively presupposed. Finally, real possibilities can also differ in the weight with which they entice a positing assumption.

The assumption of real possibilities relating to empirical things is most often motivated by former experiences of real things and of the real world, and it is oriented towards an anticipation of future experiences of the same realities. Usually, these future experiences or events are not only assumed to be possible, they are expected as a future reality. They belong to the horizon of a present perception and, as such, are already virtually perceived. When a present perception reaches out to the next perception of a single real object, this obviously goes far beyond the consideration of mere real possibilities. This is why Husserl distinguishes this kind of 'potentiality' (Potentialität), which belongs to the 'horizon of expectation' (Erwartungshorizont) of an experience, from a mere possibility (Hua I, pp. 18-19). One can then further differentiate between potentialities that essentially relate to the 
nature of the object (for example the backside of a spatial thing), and potentialities that are related to the subject (for example its habits, interests, etc.). In addition, a subject that is involved in such objective and subjective potentialities not only anticipates future experiences or appearances of an object, it usually actively contributes to their realization.

The anticipation of the further course of an actual perception of a real thing is not a matter of mere phantasy, but of the perception's actual potentiality. Phantasy alone cannot account for the real possibility of a real thing and its actual perception. Assumptions about really possible experiences involve a belief, a pre-predicative affirmation that is in no way neutralized. Finally, when it comes to a subject making the future experience in question really possible, namely to its 'possibilization' (Ermöglichung), it goes without saying that imagination is of no use at all. Pure phantasy not only lacks belief in what it imagines, it also lacks the potentiality to make its imagined objects become real.

This does not mean, however, that possibilities related to real empirical objects do not lend themselves to acts of imagination. It only means that imagination is different from an anticipation or expectation, and that imagination alone cannot account for, or justify the assumption or affirmation of a possibility - especially a real possibility. Only an original intuition can legitimate the position of a real possibility: a sensible perception in the case of empirical objects, and an intellectual intuition in the case of ideal objects. Even though imagination remains a privileged way to leave the mere observation of real facts behind and to consider possible events, it is not imagination that makes these events really possible. We must thus say: 1) The belief or affirmation that what one imagines is really possible belongs to an act that goes beyond the content of an act of imagination. 2) Whether this subjective belief or affirmation is legitimate or not, depends on an original intuitive experience and knowledge of the nature of the object and of the real world, and not on imagination.

The first statement is in need of more nuance. We have seen that a phantasy-ego can very well be concerned with the consistency of what he imagines. Yet, he does not care whether or to what extent his phantasy-world could possibly become real. Such a care can only be ascribed to the real-ego who actually accomplishes the act of a pure phantasy - but not insofar as he does this and only this. When the realego wonders about the possible reality of what he imagines or when he assumes it positively, this comes in addition to his phantasies. For example, one wonders subsequently whether what one has imagined with pleasure, could possibly become real. In a more theoretical attitude, one can use one's pure phantasies to explore possible aspects of the real world one has never experienced so far. In both cases, the realego makes an instrumental or methodological use of his pure phantasies, a use that is foreign to their normal function. In doing so, the ego takes advantage of what we have called the 'double life' of the subject involved in imagination.

The second statement moves us into the realm of phenomenological, ontological, and logical considerations about possibilities. Whether what one imagines is truly really possible depends on its compatibility with all that we authentically know about the nature of reality. Most things we know about the nature of empirical reality come from our (shared!) effective perception of it. The justification of our belief that what we imagine could possibly become real depends thus on our intuitive 
empirical knowledge of the real world. Given that this knowledge is far from being adequate, our belief in the real possibility of the empirical objects that we imagine is never entirely justified. ${ }^{6}$

\section{Imagination and Ideal Possibilities Prescribed by Essences}

Husserl believes, however, that not everything we know about the real world comes from our empirical intuitive experience of real facts. Real facts depend on both empirical and ideal conditions of possibility. Formulated in Husserl's language, this means that all empirical facts 'have' an essence, and that this essence governs their ideal possibility. We must thus keep in mind our former distinction between ideal possibilities that are unreal or opposed to a real possibility, and ideal possibilities that are irreal and in agreement with a real possibility. The former are merely imaginary possibilities for the assumption of which 'nothing speaks,' the latter are essential and necessary conditions of the possibility for both empirical and ideal objects. Regarding the latter form of ideal possibilities, Husserl further distinguishes between logical and ontological ideal conditions of possibility, and he carefully analyses, for both of them, their different levels or degrees of formalization. Most important in our present context is, however, the insight that real and ideal conditions of possibility do not exclude each other. Quite to the contrary: what is really possible must also be ideally possible (Hua XX/1, pp. 178-179). An event or course of events that one imagines can thus possibly become real only when, in addition to its compatibility with the nature of empirical reality, it satisfies the rules of logical and ontological consistency.

For Husserl, what he calls the essence of an empirical object cannot be grasped in the same way as we experience the object itself. The essence of a table remains, however, a true object, because it has its proper kind of (irreal) existence and lends itself to an intuitive experience sui generis. Husserl calls this experience an 'intuition of essence' (Wesensschau), or an eidetic intuition. He also uses the term 'Wesensanschauung' to emphasize that the intellectual intuition of an essence is a kind of perception - though not a straightforward one like the perception of an empirical object. In Husserl's final account, such an intuition of an essence is obtained by means of an 'eidetic variation.' This is a 'free' variation of examples that allows for the intuitive givenness of their invariant common essence. The freedom of this variation is thus geared towards a delimitation of what binds the variable examples together.

In this variation, variable real empirical objects, properties or facts are de-contextualized, de-factualized or, better, de-realized to allow for an insight into their common ideal essence. De-realized objects remain empirical objects, the existence of which has, however, been neutralized. In the operation of an eidetic variation a manifold of different neutralized or unreal empirical objects of a certain kind (for

\footnotetext{
${ }^{6}$ Cf. Hua III, 1, § 24, p. 51: "Am Prinzip aller Prinzipien: daß [...] alles, was sich uns in der ,Intuition" originär [...] darbietet, einfach hinzunehmen sei, als was es sich gibt, aber auch nur in den Schranken, in denen es sich da gibt, kann uns keine erdenkliche Theorie irre machen."
} 
example different tables) become variable examples or instances of one and the same irreal essence (table in general). This general essence of all tables can be further formalized and then it becomes, in its turn, a specific example of a more general essence, such as 'something in general.' The same eidetic treatment can also be applied to predicative judgments, and even to our experience of all kinds of intentional acts and objects. This is to say that, in addition to ontological eidetic considerations, logical objects, such as meanings, and phenomenological objects, such as the acts of intentional consciousness, also lend themselves to an eidetic approach.

What is then the relation between essences (or the eidetic sciences built on them) and imagination? And what is the relation between essences and possibilities?

To answer the first question, we must remind ourselves of pure phantasy's refraining from taking its intentional object to actually exist in an empirical reality. Since a de-realization of variable empirical objects is the first step leading to the intuition of their common essence, and since imaginary objects are, by definition, unreal (in the sense of being only quasi-real), we are allowed to think that the imaginary objects of a pure phantasy are best suited as examples for the intuition of an essence. Equally, the free eidetic variation of de-realized or imagined objects is most easily and most efficiently carried out in an act of imagination. Imagination thus becomes, for Husserl, the royal way leading to the intuition of essences and to the formation of eidetic sciences - including phenomenology. We now understand better how he could consider " "fiction' [as] the vital element (Lebenselement) of phenomenology" (Hua III, $1, \S 70)$.

\section{Eidetic Sciences and Sciences of Facts}

Turning to the second question, we must keep in mind that the intuition of an essence, while best initiated by an imaginative variation of imagined objects, is not itself an act of imagination. Essences are true, not imaginary objects. They have their own kind of existence that is not 'unreal,' but 'irreal.' Just as a sensible perception is required for the justification of a belief in the real existence of empirical objects, only an act of true eidetic intuition (and no intuitive pure phantasy) can justify the ideal existence of an essence. In whatever way one may account for their existence (in terms of validity, of lawfulness, of region or realm, etc.), essences are neither imagined objects nor merely possible objects. Their relation to possibility rather consists in allowing for a possibility, or in lawfully prescribing the condition of possibilities.

Essences not only allow for ideal possibilities concerning ideal objects. They also allow for real possibilities concerning empirical facts or real things, and real possibilities concerning an intuitively fulfilled experience of them. Yet, essences can in no way help realize the possibilities they normatively prescribe. The real existence of an empirical thing or of an individual fact can never be deduced from an intellectual insight into the nature of an essence. This limitation marks a constraint, but also an opening. On the negative side, eidetic sciences can never completely substitute themselves for sciences of facts (Tatsachenwissenschaften). On the positive side, eidetic sciences formulate ideal laws, the validity of which is not restricted to 
already existing empirical sciences. These laws also apply to novel empirical sciences, which eidetic sciences can help bring into view or help to promote.

Phenomenology as an intuitive eidetic science concerning the intentional correlation between mental events and objective phenomena does more than this. It formulates the ideal conditions of possibility for all existing empirical sciences of nature and spirit, it allows for the establishment of a new transcendental phenomenology as a rigorous science, and it contributes to a reformation of the already existing empirical and eidetic sciences. As an eidetic science based on the imaginary variation of mainly imagined intentional mental events, Husserl's phenomenology appeared to many (including phenomenological) critics as living on the thin air of a Platonic ideal space. These critics mistook the distinction between fact and essence to indicate a radical ontological separation. However, Husserl made clear that, just as all facts 'have' an essence (Hua III/1, § 2), all essences and eidetic sciences eventually refer back to facts (Hua XVII, § 82). Consequently, the phenomenological eidetic (and transcendental) science of intentional consciousness cannot be said to lose all interest in the factual experiences of real persons and in the existence of the real world. Husserl's intuitive eidetic and transcendental phenomenology just investigates these facts, with the help of imagination, as ideal or, better, really irreal possibilities.

Acknowledgements The author wishes to thank the anonymous reviewer for his or her valuable suggestions, and also John B. Brough, whose work has remained his constant source of inspiration for several decades

\section{Work cited $^{7}$}

Bernet, R. (2005). Real Time and Imaginary Time: On the Husserlian Conception of Temporal Individuation. In G. Banham (Ed.), Husserl and the Logic of Experience (pp. 217-236). London/New York: Palgrave Macmillan.

Publisher's Note Springer Nature remains neutral with regard to jurisdictional claims in published maps and institutional affiliations.

\footnotetext{
${ }^{7}$ For full references to the Husserliana series, please see the shared bibliography, at the end of the guest editors' introduction, for the Husserl Studies special issue this paper is part of.
} 